\title{
ESTUDO COMPARATIVO DO SUFIXO-ARÍA/-ERÍA NAS LÍNGUAS GALEGA E ASTURIANA EM CONTRASTE COM A LÍNGUA PORTUGUESA
}

\begin{abstract}
Valéria Gil Condé*
Resumo: Este artigo pretende analisar comparativamente o sufixo -aría/-ería nas línguas galega e asturiana em contraste com a língua portuguesa. Com base nos estudos propostos pelo Grupo de Pesquisa intitulado Morfologia Histórica do Português da Universidade de São Paulo (www.usp.br/gmhp), demonstraremos que o referido sufixo apresenta as mesmas significações semânticas em ambas as línguas, preservando, dessa forma, a unidade românica. Em um segundo momento, procuraremos inserir o sufixo no contexto hispânico com o propósito de verificar a interferência da língua castelhana. Do ponto de vista político, o galego encontra-se em condição de cooficial em relação ao castelhano, o que não se verifica nas Astúrias, pois a língua asturiana não é considerada língua oficial pelo Estatuto de Autonomia, fato que favorece o castelhano, que se mantém como língua soberana.
\end{abstract}

Palavras-chave: Linguística românica; morfologia; derivação; línguas iberorromânicas.

* Universidade de São Paulo. 


\section{Escrita latina e escritas romances na Asturia e na Gallaecia}

No processo de romanização da Hispania, tanto a Gallaecia quanto a Asturia foram as últimas regiões a serem romanizadas, em 19 a.C. Esses povos resistiram vigorosamente à presença dos romanos. Com características culturais semelhantes, essas regiões ágrafas apreenderam a escrita e o alfabeto latinos. Os romanos no seu processo de latinização não aceitavam as línguas dos povos vencidos, a única aceita foi a grega. Sob o domínio romano, em toda a Hispania, não se conhece nenhum documento escrito em língua autóctone ou bilíngue, como nos afirma Monteagudo. ${ }^{1}$ Cumpre lembrar que os ibéricos e os tartesos, também habitantes da Hispania pré-romana, possuíam alfabetos próprios, e ainda assim foram permeáveis à escrita e alfabeto latinos, tão ou mais rapidamente que os habitantes do Noroeste Peninsular.

Após a fragmentação do Império Romano no século $\mathrm{V}$, os romances de origem latina, quais sejam, o galego e o astur-leonês, só emergiram como língua escrita somente em meados do século XIII e em alguns tipos de textos e gêneros discursivos. Em galego, por exemplo, os gêneros, poesia e prosa literárias foram escritos a partir do século XIII e desaparecem em favor do castelhano nas primeiras décadas do século XVI. Os documentos da prosa administrativa, escritos em latim até o século XIII, aos poucos, cedem espaço para o galego a partir desse século, mais precisamente nos reinados de Fernando III e de Afonso X (1252-1284). Assistiremos, também, a partir do século XVI, a incursão do castelhano como língua escrita na administração da Galiza.

Nas Astúrias, o século XIII ensejou a escrita medieval asturiana, especialmente em textos jurídicos, como também em textos literários. Já na segunda metade do século XIV, observa-se uma crescente castelhanização dos documentos da região.

\footnotetext{
${ }^{1}$ MONTEAGUDO. História social da língua galega, p. 57.
} 
Duas regiões, duas sócio-histórias com um passado comum. O castelhano, como língua de cultura, impõe-se nas duas regiões. A partir de então, formaliza-se o bilinguismo, em situação diglóssica: língua escrita de prestígio, em situação de comunicação formal, a castelhana; língua informal, em ambientes rurais e familiares, tanto a galega quanto a asturiana. Na Galiza e nas Astúrias, as classes dirigentes, funcionários eclesiásticos e civis a partir do século XVI são falantes de castelhano.

\section{O século XX e a situação política das línguas asturiana e galega}

Ao contrário do que sucedeu à língua galega, a língua asturiana não goza do status de língua cooficial, pois na época da reforma do Estatuto de Autonomia nas Astúrias, em 1998, não a qualificaram como língua oficial ao lado do castelhano. Apesar de não se encontrar oficializada e em região considerada bilíngue, $o$ asturiano ainda é falado majoritariamente por idosos em áreas rurais; já em áreas urbanas, perde espaço para o castelhano. $\mathrm{O}$ galego, apesar de se encontrar em condição de oficialidade, ao lado do castelhano, ainda é transmitido majoritariamente em ambiente familiar, ainda que a escola, segundo o censo de 2004, devido à oficialização da língua, demonstrou sua força na aquisição do galego. ${ }^{2}$ Do ponto de vista social, o galego ainda se encontra vinculado a pequenos centros urbanos, a grupos menos dinâmicos da sociedade galega e com baixa escolaridade, contrariamente ao que ocorre ao castelhano, que é veiculado nos grandes centros urbanos e falado por pessoas de nível escolar mais elevado. Não nos esqueçamos, entretanto, que as línguas galega e asturiana estiveram em situação de desprestígio de sua modalidade culta, oral e escrita, a partir do século XVI.

${ }^{2}$ GONZÁLEZ GONZÁLEZ. Mapa sociolingüístico de Galicia 2004, p. 134. 
Apresentadas as sócio-histórias das línguas, passaremos ao estudo de um sufixo muito produtivo na România, herdado do latim, o sufixo -aría e sua variante-ería. Como propostas para este artigo, trataremos de verificar:

a) se a herança latina foi mantida por meio do latim vulgar ou se deu por meio de empréstimos de alguma das línguas românicas;

b) qual a forma mais usual na România Ibérica, se -aría ou -ería;

c) se houve ampliação semântica do sufixo a partir do latim clássico e vulgar;

d) se as paráfrases geradas pelo sufixo são as mesmas nas línguas em estudo;

e) se houve interferência do castelhano.

\section{Corpus e metodologia}

O corpus utilizado para este estudo foi retirado de uma lista quantitativa a partir do dicionário asturiano (www.academiadelallingua.com/diccionariu), o qual foi posteriormente comparada à gramática e dicionários. Buscamos, quando possível, inventariar as mesmas palavras comuns às línguas românicas da Península Ibérica, para tanto, em português, as palavras derivadas em-aria/-eria foram retiradas do Dicionário Houaiss; ${ }^{3}$ em galego, o inventário das palavras formadas por -aría/-ería foi retirado do Dicionário da Real Academia Galega. ${ }^{4}$ Dessa forma, poderemos estabelecer as paráfrases e verificar possíveis semelhanças e diferenças.

Com base em metodologia específica, desenvolvida pelo Grupo de Morfologia Histórica do Português, para o presente

\footnotetext{
${ }^{3}$ HOUAISS; VILLAR. Dicionário Houaiss da língua portuguesa.

${ }^{4}$ REAL ACADEMIA GALEGA. Diccionario da Real Academia Galega.
} 
artigo, valemo-nos dos estudos da Dialetologia, da Sociolinguística e da Linguística Românica, com a finalidade de perseguir a origem do sufixo, bem como as heranças lexicais partilhadas pelas línguas pesquisadas.

\section{Origem do sufixo-aria}

Os processos de formação de palavras das línguas românicas foram herdados das variedades clássica e vulgar do latim. As línguas românicas, após a fragmentação do Império Romano, ora preservaram, ora inovaram o seu acervo, valendo-se dos processos oriundos da língua latina. É o que verificamos na formação do sufixo-aría/-ería.

Segundo Said Ali, ${ }^{5}$-aria originou-se da junção do sufixo -ia aos derivantes terminados em -eiro.

Valemo-nos das posições de Maurer Jr. ${ }^{6}$ e Väänänen: ${ }^{7} \mathrm{o}$ primeiro acusa a sua origem a partir do feminino ou do neutro plural de-arius; o segundo sugere que verbos como facĕre "fazer", complementados pelo objeto e seu complemento, sofreram elipse em latim vulgar, como no exemplo taberna ou ars agentaria, resultando, dessa forma, em argentaria "banco". Encontramos em Cícero (Filípicas, 2, 21) libraria taberna com sentido de "biblioteca". A origem pan-românica atesta essa formação, sirvam-nos de exemplo, livraria ("biblioteca"), cuja elipse em latim vulgar culminou nas seguintes formas: em português, livraria; em galego, asturiano e castelhano, librería; em catalão oriental e balear llibreria [Кibrə'riə], em valenciano [Kibre'ria]; em italiano, libreria; em provençal moderno, librariá [libra'rje], em francês, librairie. Vale ressaltar que o sufixo francês

\footnotetext{
${ }^{5}$ SAID ALI. Formação de palavras e syntaxe do português bistórico, p. 5.

${ }^{6}$ MAURER JR. Gramática do latim vulgar, p. 263.

${ }^{7}$ VÄÄNÄNEN. Introducción al latín vulgar, p. 156.
} 
originado de -aria, que resultou em -erie, librairie, foi grafado $<$ airie $>$ para manter a etimologia latina. ${ }^{8} \mathrm{O}$ romeno, influenciado pelo francês e italiano, recebeu como empréstimo librărie [librə'rie]. Apesar do breve período em que esteve sob o domínio latino entre 106-270 d.C., o romeno, no século XIX, sofreu um processo de relatinização e recebeu tanto do italiano quanto do francês inúmeros empréstimos, ampliando, dessa forma, o seu acervo de origem românica.

Tekavčic ${ }^{9}$ sugere a redução de -arius, ou seja,-ar, com a união do sufixo grego-ía, origem partilhada também por Cunha. ${ }^{10}$

\section{Deslocamento do acento, perda da quantidade vocálica do sufixo-aria e surgimento de-eria}

O latim vulgar operou uma transformação profunda a partir das características das vogais do latim clássico. Essa remodelação priorizou a oposição de timbre vocálico em detrimento da duração vocálica. Longe de ser unificada, essa mudança ocasionou nas línguas romances sistemas diferenciados e complexos. As vogais breves latinas, por exemplo, sofreram modificações consideráveis. No chamado Sistema Qualitativo Itálico do latim vulgar, em posição tônica, a evolução de [o] é o resultado

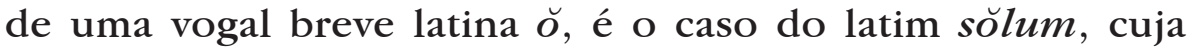
modificação tanto em português quanto em galego será de $s[0] l o$; tal desdobramento resultou na ditongação espontânea em castelhano: veja-se, do latim, solum $>* s[$ wo]lo $>s$ [we]lo. Há exceções, entretanto, pois estamos falando de variedade oral. É o caso, por exemplo, da vogal breve latina $\breve{\imath}$ como em $d \grave{\imath}$ gnus, que não resultou em [e], ao contrário, permaneceu como uma palavra

\footnotetext{
${ }^{8}$ LAUSBERG. Lingüística românica, p. 120.

9 TEKAVÈIC. Grammatica storica dell'italiano, p. 40.

${ }^{10}$ CUNHA. Dicionário etimológico Nova Fronteira da língua portuguesa, p. 66.
} 
culta - digno - tanto em galego quanto em português. Este não foi o caso do italiano e do provençal que modificaram para degno e denh, respectivamente. No latim vulgar, o timbre vocálico ficou indistinto para o $a$ que, além de perder a sua quantidade vocálica, não diferenciou a sua abertura, é o que podemos verificar entre as vogais tônicas longas e breves, como em latim, lātus que resultou em português lado; galego lado; romeno lat; castelhano lado; provençal latz; francês arcaico lez; italiano lato. Do latim, cabăllus, que resultou em português cavalo; galego cabalo; em romeno cal; castelhano caballo, catalão, cavall; provençal antigo e moderno caval, francês cheval, italiano cavallo. Não podemos deixar de mencionar que a palatalização de $a$ em francês é proveniente da sua posição em sílaba livre. Para o problema do deslocamento do acento oxítono de -aria/-eria, sugerimos o caminho latim culto via francês e que se disseminou para as outras línguas românicas.

Após refletir sobre a origem de -eria, que em comparação com -aria é o sufixo mais difundido nas línguas românicas, identificamos a época medieval como o período da sua difusão. $\mathrm{O}$ francês, nessa época, foi uma língua que exerceu muita influência na România Ocidental. Em francês, o $a$ tônico em sílaba livre palataliza-se em [e], dessa forma -aria resultou em -erie e se disseminou para as outras línguas. Vale lembrar que essa língua de tendência acentual oxítona também influenciou nesse aspecto as outras línguas. Como nos informa o romanista Lausberg, ${ }^{11}$ essa mudança é peculiar do francês, pois a palatalização do $a$ em posição livre consiste na principal diferença entre o francês e o provençal. $^{12}$

\footnotetext{
${ }^{11}$ LAUSBERG. Lingüística românica, p. 120.

${ }^{12} \mathrm{Cf}$. francês librairie, provençal moderno librariá.
} 


\section{O sufixo -eria nas línguas da România Ibérica}

Nas línguas românicas, o sufixo - eria é a forma majoritária. Dentre as línguas iberorromânicas, o português é a única língua que possui formas majoritariamente sufixadas por-aria. Nas línguas asturiana e galega, apresentam-se poucas formas sufixadas por - aría, mas sem dúvida a forma -ería é a mais produtiva e mais usual. Para a forma sufixada em -aría, sirvam-nos de exemplo romaría, comisaría, secretaría.

No caso da língua galega, a partir de 2003, uma nova proposta normativa sugeriu que o sufixo-aría, resultado fonético da forma latina -aría e forma majoritária do galego medieval, fosse priorizado em detrimento de -ería. Essa é uma proposta recémimplantada, a forma usual ainda é majoritariamente -ería.

$\mathrm{Na}$ língua portuguesa, registramos o sufixo -aria, cuja origem remonta ao latim e é a forma mais usual. Pelos estudos dialetológicos, esse sufixo apresenta uma demarcação da uma linha que acusa uma relíquia linguística, pois a separa das outras línguas da Península Ibérica. Foi possível, a partir dos 658 verbetes listados no Dicionário Houaiss ${ }^{13}$ terminados em -aria e-eria, entrever que a forma minoritária é-eria com oitenta e oito verbetes, dos quais quarenta e seis se encontram com data de entrada da palavra na língua. No século XIII, por exemplo, das palavras sufixadas por-aria e-eria do século XIII, a única terminada em eria é parceria, registrada em 1209. Podemos observar, no entanto, que o sufixo -eria foi ampliando o seu acervo. Assim, no século $\mathrm{XV}$, temos cavaleria; no XVI, galanteria, altaneria, correria, grosseria, sobranceria, rancheria, bateria; no XVII, registram-se alqueria, poltroneria, lavanderia, vozeria, volateria, galeria; no século XVIII, loteria, calaceria, mamposteria; no século XIX, serralberia, pedanteria, almocreveria, bijuteria, selvageria, almocreveria, bodomeria; no século XX, bilbeteria, charcuteria,

\footnotetext{
${ }^{13}$ HOUAISS; VILLAR. Dicionário Houaiss da língua portuguesa.
} 
clicheria, carroceria, cristaleria, rotisseria, joalberia, creperia, choperia, bateria, cafeteria, leiteria, biscouteria, peleteria, sorveteria, uisqueria, danceteria, escuderia, lambateria, organeria.

$\mathrm{O} \mathrm{gráfico}^{14}$ subsequente demonstra como as formas-aria/ -eria apresentam-se ao longo dos séculos na língua portuguesa. O sufixo -aria, forma inicialmente mais disseminada, vem perdendo paulatinamente espaço. Postulamos, para essa questão, o fato de outros sufixos concorrerem do ponto de vista do conteúdo semântico com -aria. A variante-eria, por ter ampliado o seu acervo pode ter ensejado essa perda. Alguns comentários sobre essa mudança serão apresentados a seguir.

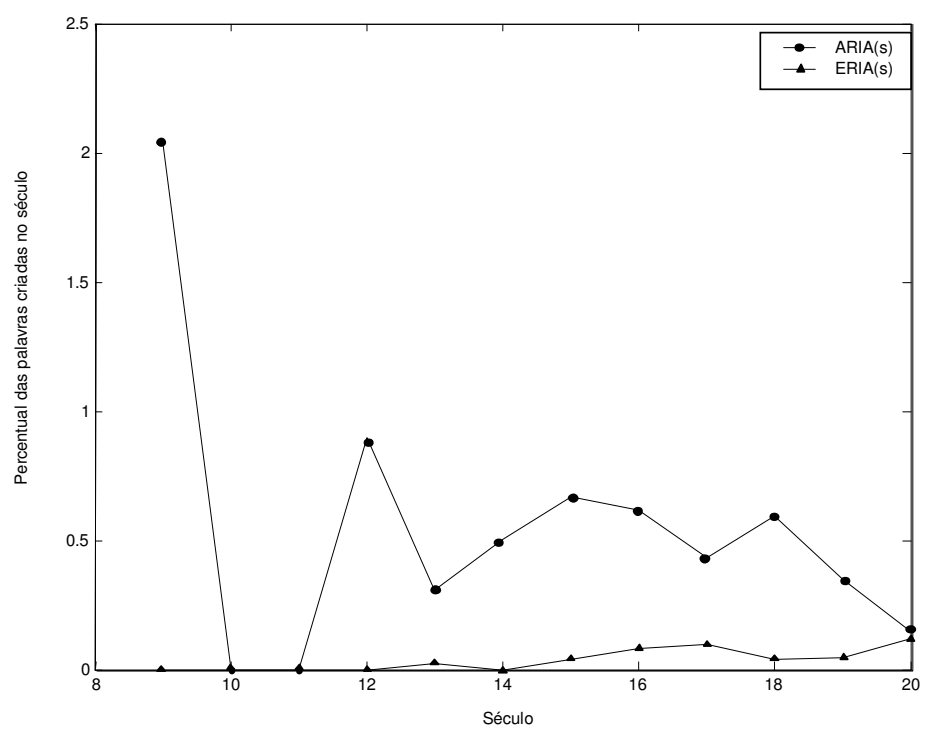

GRÁFICO 1: Formas - aria/-eria ao longo dos séculos na língua portuguesa

Primeiramente constatamos a concorrência de alguns dos campos semânticos ocupados por-aria/-eria com o de outros sufixos - comparem-se por exemplo:

${ }^{14}$ Gráfico elaborado por Zwinglio O. Guimarães-Filho e Leandro Mariano, pesquisadores do Instituto da Física da Universidade de São Paulo e integrantes do Grupo Morfologia Histórica do Português. 
a) Para o significado de "grande quantidade ou conjunto de X",-aria/-eria concorre com-ura,-agem, -ção, -ada,ama, -eira, como em roncaria roncadura; trocaria troncagem; açougaria açougada; piolbaria piolbada piolbama piolbeira;

b) Para o significado de "ação de $\mathrm{X}$ ", -aria/-eria concorre com -ura, -agem, -ada, -ice, como em roncaria roncadura; pilharia pilhagem; futricaria $\sim$ futricada futriquice futricagem;

c) Com o significado de "propriedade de ser $\mathrm{X}^{\mathrm{p}}$ (base predicativa ou adjetival/participial)", o sufixo-aria/-eria concorre com-agem,-ice,-ada,-ia,-idade,-ez(a), como em camaradaria camaradagem; bisbilboteria bisbilbotice; futricaria $\sim$ futricada $\sim$ futriquice $\sim$ futricagem; rusticaria $\sim$ rusticidade $\sim$ rustiquez $\sim$ rustiqueza.

Não poucas vezes, a forma concorrente-eria é proveniente de empréstimos recebidos de outras línguas românicas. Para corroborar, vejam-se selvageria, proveniente do francês sauvagerie selvajaria; rancheria, do castelhano ranchería rancharía; galanteria, proveniente do francês galanterie galantaria; charcuteria, do francês charcuterie charcutaria; loteria, do italianolotteria lotaria; botelaria boteleria, do francês bôtellerie; ladraria ladreria, proveniente do francês ladrerie; joalheria (com data de registro na língua escrita em 1950) e joalharia (1881), ambas classificadas por Houaiss como empréstimos do francês joailleire (datação francesa de 1434). Vale observar que esses vocábulos foram tomados de empréstimos das línguas românicas em diferentes momentos históricos como no caso de joalberia joalbaria.

O sufixo -eria na língua portuguesa resulta também de substantivos, cuja vogal temática nominal -e na palavra base resulta em -eria - sirvam-nos de exemplo chope $\rightarrow$ choperia, ou ainda, formas mais usuais como sorvete $\rightarrow$ sorveteria e leite $\rightarrow$ leiteria, que se contrapõem às menos usuais sorvetaria e leitaria. 


\section{Significado do sufixo}

Väänänen ${ }^{15}$ afirma que, se em latim o sufixo significava "nomes de ofício ou de comércio, usados sobretudo como complemento de objeto de facere", nas línguas romances houve uma ampliação de sentido com especial significação de "quantidade de algo ou lugar em que se encontra algo em grande quantidade".

A partir do corpus do Diccionario da Real Academia Galega ${ }^{16}$ foram propostas as seguintes paráfrases ${ }^{17}$ para-aría/-ería:

a) "Local onde há X (base nominal)" - LOC: armería, cafetería, carnicería, cervexería, chancelería, chocolatería, concellería, confeitería, consellería, codoería, cristalería, docería, droguería, ferraxería, ferrería, froitería, berboristería, lavandería, leitería, lencería, leprosería, librería, marroquinería, panaderia, papelería,pastelería, peixería, peletería, pizzería, portería, reloxería, tesourería, tinturería, comisaría, secretaría .

b) "Local onde se Xv (base verbal)" - LOCA (local da ação): barbería, destlilería, gardería, refinería.

c) "Atividade (ofício) associada a X (base nominal)" - ATV: albanelería, cantería, carpintería, chancelería, ebanistería, bostalería, marroquinería, minería, ourivería, perfumería, piratería, repostería, tapicería, xardninería, xastrería, xeadería, xoiería, zapatería, notaría, romaría, secretaría.

d) "Conjunto, quantidade de X (base nominal)" - QNT: minería, pedrería, pradería, confraría, romaría, infantería, gandería, enxeñería, cristalería, carnicería, batería, albetería.

\footnotetext{
${ }^{15}$ VÄÄNÄNEN. Introducción al latín vulgar, p. 147.

${ }^{16}$ REAL ACADEMIA GALEGA. Diccionario da Real Academia Galega.

${ }^{17}$ As paráfrases utilizadas fazem parte de um manual desenvolvido pelo Grupo de Morfologia Histórica do Português a partir dos estudos propostos por RioTorto (Morfologia Derivacional. Teoria e aplicação ao português).
} 
e) "Propriedade de (C) ser $\mathrm{X}^{\mathrm{p}}$ ou que é $\mathrm{X}^{\mathrm{p}}$ (base predicativa ou adjetival/participial), onde (C) é o complemento sintático preposicionado da palavra formada" - ESS: beatería, chulería, coquetería, feiticería, galantería, grosería, pedantería, tolería.

f) "Ação de $\mathrm{X}^{\mathrm{v}}$ (base verbal), o fato de $\mathrm{X}^{\mathrm{v}}$ " - RES: cetrería, piratería, pratería, puntería.

g) "Instrumento (com) que (se) X" - INS: cabalería.

A língua portuguesa apresenta as mesmas significações semânticas que a língua galega, como atestam as paráfrases descritas a seguir:

a) "Local onde há X (base nominal)" - LOC: aceria, carniceria, carroceria, amideria, lavanderia, clicheria, joalberia, serralberia, galeria, cristaleria, peleria, creperia, choperia, lamaseria, nurseria, rotisseria, lambateria, cafeteria, bilbeteria, peleteria, sorveteria, leiteria, escoteria, talabateria, ebanesteria, charcuteria, luteria, alqueria, coqueria, uisqueria.

b) "Local onde se Xv (base verbal)" - LOCA (local da ação): engraxeteria, danceteria.

c) "Atividade (ofício) associada a X (base nominal)" - ATV: clicheria, joalheria, serralheria, cristaleria, peleria, organeria, altaneria, volateria, encanteria, loteria, talabarteria, ebanesteria, charcuteria, biscouteria, almocreveria .

d) "Conjunto, quantidade de X (base nominal)" - QNT: esnoberia, parceria, tolderia, clicheria, joalberia, serralberia, artilheria, galeria, cavaleria, peleria, boteleria, frusseria, bateria, contrabateira, volateria, pedanteria, infanteria, charcuteria.

e) "Propriedade de $(C) \operatorname{ser} \mathrm{X}^{\mathrm{p}}$ ou que é $\mathrm{X}^{\mathrm{p}}$ (base predicativa ou adjetival/participial), onde (C) é o complemento sintático preposicionado da palavra formada" - ESS: esnoberia, calaceria, sobranceria, terceria, selvageria, 
altaneria, poltroneria, glutoneria, grosseria, coqueteria, galanteria, bisbilboteria.

f) "Ação de $\mathrm{X}^{\mathrm{v}}$ (base verbal), o fato de $\mathrm{X}^{\mathrm{v}}$ " - RES: carniceria, gaucheria, correria, bateria, barganteria, galanteria, bisbilboteria, vozeria.

g) "Instrumento (com) que (se) X" - INS: minuteria.

h) "Doença associada a X" - DOE: ladreria.

Em asturiano, a partir do dicionário já referido (www.academiadelallingua.com/diccionariu), propomos as seguintes paráfrases para-ería/-aría:

a) "Local onde há X (base nominal)" - LOC: armería, bixutería, cafetería, carnicería, cervexería, concellería, chico latería, concellería, confeitería, consellería, codoería, cristalería, droguería, ferretería, ferrería, frutería, galería, llavandería, leitería, lencería, lleprosería, llibrería, marroquinería, panaderia,papelería, pastelería,pescadería, peletería, pizzería, portería, reloxería, tesourería, tinturería, comisaría, secretaría, sedería, caballería .

b) "Local onde se $\mathrm{X}^{\mathrm{v}}$ (base verbal)" - LOCA (local da ação): babayería, destilería, guardería, refinería.

c) "Atividade (ofício) associada a X (base nominal)" - ATV: cantería, carpintería, ebanistería, bostelería, minería, perfumería, piratería, repostería, tapicería, xardinería, xastrería, sastrería, xoyería, zapatería, notaría, romaría, secretaría.

d) "Conjunto, quantidade de X (base nominal)"-QNT: minería, pedrería, pradería, confraría, romaría, infantería, gandería, enxeñería, cristalería, carnicería, batería, albetería, xeladería, llotería, rapacería, cubertería, follería.

e) "Propriedade de $(\mathrm{C}) \operatorname{ser} \mathrm{X}^{\mathrm{p}}$ ou que é $\mathrm{X}^{\mathrm{p}}$ (base predicativa ou adjetival/participial), onde (C) é o complemento sintático preposicionado da palavra formada" - ESS: 
beatería, chulería, coquetería, bruxería, galanería, grosería, pedantería tontería, santería, soltería, pallabería, aparcería, rapacería.

f) "Ação de $\mathrm{X}^{\mathrm{v}}$ (base verbal), o fato de $\mathrm{X}^{\mathrm{v}}$ " - RES: piratería, pratería, puntería.

\section{Considerações finais}

Do ponto de vista semântico, o sufixo-aria/-eria mostrouse produtivo e demonstrou que a partir do latim houve uma ampliação substancial das acepções. Podemos inferir que o francês contribuiu para a manutenção da unidade românica, pois o sufixo - eria, cuja formação remonta ao francês, disseminou-se para todas as línguas românicas. O Noroeste Peninsular, ao apresentar preferência por -ería, reafirma a unidade românica em geral e iberorromânica em particular. Não podemos afirmar, portanto, que houve a influência direta do castelhano nessa formação, entretanto não podemos deixar de observar que estas línguas estão em constante contato. A forma -aria é a forma mais produtiva em português e somente nesta língua mantém-se, apesar de vir perdendo força no século XX, como demonstrou o gráfico das ocorrências dos sufixos-aria/-eria. Podemos classificá-la como uma forma relíquia no contexto iberorromânico, bem como de toda a România.

Resumen: Este artículo tiene la pretensión de establecer un análisis comparativo de los sufijos -aría/-ería entre las lenguas gallega y asturiana en contraste con la lengua portuguesa. Con base en los estudios propuestos por el Grupo de Investigación nombrado Morfologia Histórica do Português de la Universidad de São Paulo (www.usp.br/ gmhp), demostraremos que dicho sufijo presenta las mismas significaciones semánticas en ambas lenguas, conservando de esa forma la unidad románica. En segundo lugar, buscaremos insertar el sufijo en el 
contexto hispánico con el fin de verificar la interferencia de la lengua castellana. Desde un punto de vista político, el gallego se encuentra en condición de co-oficialidad, respecto al castellano, lo cual no se verifica en Asturias, pues a la lengua asturiana no se considera como oficial en el Estatuto de Autonomía, hecho que le favorece al castellano, que se mantiene como lengua soberana.

Palabras-llave: Linguística románica; morfología; derivación; lenguas iberorrománicas.

\section{Referências}

ÁLVAREZ, R.; REGUEIRA, X. L.; MONTEAGUDO, H. Gramática galega . Vigo: Galáxia, 1995.

CHAMBERS, J.K.; TRUDGILL, P. Dialectology. Cambridge: Cambridge University Press, 1990.

ACADEMIA DE LA LLINGUA ASTURIANA. Gramática de la llingua asturiana. Oviedo: Academia de la llingua asturiana, 2001.

CUESTA, P. V.; LUZ, M. A. M. da. Gramática da língua portuguesa. Lisboa: Edições 70, 1989.

CUNHA, A. G. da. Dicionário etimológico Nova Fronteira da língua portuguesa. Rio de Janeiro: Nova Fronteira, 1982.

CUNHA, C. F. da; CINTRA, L. F. Nova gramática do português contemporâneo. Rio de Janeiro: Nova Fronteira, 2001.

GONZÁLEZ GONZÁLEZ, M. et al. (Dir.). Mapa sociolingüístico de Galicia 2004. A Corunha: Real Academia Galega/Seminário de Sociolingüística, 2007.

HOLTUS, G.; METZELTIN, M.; SCHIMIT. C. (Org.). Lexikon der romanistischen Linguistik. Tübingen: Max Niemeyer Verlag, 1994.

HOUAISS, A.; VILLAR, M. S. Dicionário Houaiss da língua portuguesa. Rio de Janeiro: Objetiva, 2001.

LAUSBERG, H. Lingüística românica. Lisboa: Calouste Gulbenkian, 1981.

LEVY, E. Petit dictionaire provençal-français. Heildelberg: Carl Winter Universitätsverlag, 1973. 
RAMÓN LORENZO, R. A Lingua Galega, história e actualidade. In: ACTAS DO I CONGRESO INTERNACIONAL. Santiago de Compostela: Consello da Cutura Galega/Instituto da Lingua Galega, 2004. p. 27-153. MARTIN, G.; MOULIN, B. Grammaire provençale et cartes linguistiques. Aix-en Provence: Comitat Sestian d' Estudis Occitans C.R.E.O, 1998.

MAURER JR., T. H. Gramática do latim vulgar. Rio de Janeiro: Acadêmica, 1959.

MONTEAGUDO, H. História social da língua galega. Vigo: Galaxia, 1999.

REAL ACADEMIA GALEGA. Diccionario da Real Academia Galega. Vigo: Galaxia, 1997.

REAL ACADEMIA GALEGA. Normas ortográficas e morfolóxicas do idioma galego. Vigo: Real Academia Galega/Instituto da Língua Galega, 1996.

REAL ACADEMIA GALEGA. Normas ortográficas e morfolóxicas do idioma galego. Santiago de Compostela: Xunta de Galicia, 2005.

RIO-TORTO, G. M. Morfologia derivacional. Teoria e aplicação ao português. Porto: Porto Editora, 1998.

SAID ALI, M. Formação de palavras e syntaxe do português histórico. São Paulo: Melhoramentos, 1923.

TEKAVČIC, P. Grammatica storica dell'italiano. Bologna: Il Mulino, 1972.

VÄÄNÄNEN, V. Introducción al latín vulgar. Madrid: Gredos, 2003.

VASCONCELOS, J. L. de. Opúsculos. Coimbra: Imprensa da Universidade, 1929. V. IV, parte II.

WILliams, E. B. Do latim ao português. Rio de Janeiro: Tempo Brasileiro, 1975.

ZAMORA VICENTE, Alonso. Dialectología española. Madrid: Gredos, 1960.

Site:

$<$ http://www.academiadelallingua.com/diccionariu $>$. Acesso em: 16 jan. 2009.

Recebido para publicação em março de 2009.

Aprovado em maio de 2009. 